\title{
Chemoradiation Improves Survival Compared With Chemotherapy Alone in Unresected Nonmetastatic Gastric Cancer
}

\author{
Richard Li, MD; ; Wei-Hsien Hou, MD, PhDa; Joseph Chao, MD ; Yanghee Woo, MD; Scott Glaser, MD;
} Arya Amini, MDa; Rebecca A. Nelson, $\mathrm{PhD}^{\mathrm{d}}$; and Yi-Jen Chen, MD, PhD

\begin{abstract}
Background: Limited data are available to guide management of patients with stage I-III gastric cancer not undergoing potentially curative surgical resection. We compared survival outcomes associated with chemotherapy alone versus chemoradiation (CRT) in the treatment of nonmetastatic gastric cancer. Methods: Patients with gastric adenocarcinoma from 2004 to 2015 were identified using the National Cancer Database. Patients were excluded if they had surgery, metastatic disease, or T0, Tis, or T1a disease. Logistic regression was used to evaluate predictors of CRT use. Cox proportional hazards modeling was performed to compare overall survival (OS) between chemotherapy alone and CRT in overall and propensity score-matched cohorts. Results: We identified 4,795 patients with stage I-III gastric adenocarcinoma who did not undergo surgery, at a median follow-up of 11.8 months. A total of 3,316 patients (69.2\%) received chemotherapy alone and 1,479 patients $(30.8 \%)$ received CRT. Predictors of increased CRT use were age $\geq 65$ years (odds ratio [OR] 1.68; $95 \% \mathrm{Cl}, 1.43-1.99 ; P<.001$ ), Charlson-Deyo comorbidity score $\geq 2(\mathrm{OR}, 1.46 ; 95 \% \mathrm{Cl}, 1.18-1.81)$, and treatment at a community facility $(\mathrm{OR}, 1.27 ; 95 \% \mathrm{Cl}, 1.07-1.51$; $P=.006$ ). Patients receiving CRT had a 2 -year OS rate of $28.3 \%$ compared with $21.5 \%$ among those receiving chemotherapy. Multivariate analysis showed that CRT was associated with improved OS (hazard ratio [HR], 0.82; $95 \% \mathrm{Cl}, 0.77-0.89 ; P<.001$ ). After propensity score matching, a persistent survival benefit was observed $(\mathrm{HR}, 0.80 ; 95 \% \mathrm{Cl}, 0.74-0.88 ; P<.001)$. Conclusions: In patients with stage I-III gastric cancer not undergoing surgical resection, CRT was associated with improved survival compared with chemotherapy alone. However, only $30.8 \%$ of patients received CRT in this setting.
\end{abstract}

J Nat/ Compr Canc Netw 2018;16(8):950-958 doi: 10.6004/jnccn.2018.7030

Gastric cancer is the fifth most common cancer and the third leading cause of cancer mortality globally, with an estimated 28,000 newly diagnosed cases in the United States in 2017.1,2 Surgical resection, including gastrectomy and lymph node dissection, has been established as the primary curative treatment modality for locally advanced gastric cancer. ${ }^{3,4}$ Perioperative chemotherapy, adjuvant chemotherapy, or adjuvant chemoradiation (CRT) are given in conjunction with surgery based on data from phase III trials. ${ }^{5-9}$

Departments of aRadiation Oncology, bMedical Oncology, 'Surgical Oncology, and IInformation Sciences, City of Hope Medical Center, Duarte, California.

Submitted January 22, 2018; accepted for publication April 2, 2018.

Dr. Chao has disclosed that he has received grants from Merck and personal fees from Merck, Lilly, Five Prime Therapeutics, and Boston Biomedical, all unrelated to the submitted work. The remaining authors have disclosed that they have no financial interests, arrangements,
However, $>30 \%$ of patients with stage I-III gastric and gastroesophageal cancer in the United States do not undergo surgical resection. ${ }^{10,11}$ Reasons for nonsurgical management of these patients may include anatomic unresectability, medical inoperability due to comorbidities, limited access to specialized surgical care, or patient choice. ${ }^{12,13}$ The optimal management of patients who do not receive curative resection for nonmetastatic gastric cancer is unclear. Consensus treatment guidelines have divergent recommendations

affiliations, or commercial interests with the manufacturers of any products discussed in this article or their competitors.

Author contributions: Study concept: Li, Amini, Chen. Study methodology: All authors. Data analysis: All authors. Manuscript preparation: All authors Study supervision: Chen.

Correspondence: Yi-Jen Chen, MD, PhD, Department of Radiation Oncology, City of Hope Medical Center, 1500 East Duarte Road, Duarte, CA 91010. Email: yichen@coh.org 
in this setting. NCCN Clinical Practice Guidelines in Oncology (NCCN Guidelines) for Gastric Cancer recommend consideration of CRT versus palliative management (potentially involving chemotherapy alone depending on performance status), ${ }^{14}$ whereas ESMO and Japanese Gastric Cancer Association (JGCA) guidelines recommend palliative chemotherapy. ${ }^{15,16}$

Early trials in gastric cancer by the Gastrointestinal Tumor Study Group (GITSG) and Mayo Clinic showed poor survival outcomes with CRT in the absence of curative surgery, although patients receiving CRT in these studies experienced significant treatment toxicity. ${ }^{17-19}$ Both chemotherapy and radiation therapy (RT) techniques have advanced significantly since the completion of these trials. More recent phase II trials showed favorable outcomes with combined CRT, but these are single-arm studies. ${ }^{20,21}$ No contemporary studies, either randomized or retrospective, have compared chemotherapy versus CRT in patients with unresected nonmetastatic gastric cancer.

Given the lack of data addressing management in this setting, we used the National Cancer Database (NCDB) to compare survival outcomes for chemotherapy alone versus CRT in patients with stage I-III gastric cancer, focusing on patients who did not undergo surgical resection.

\section{Methods}

The NCDB is a national oncology database sponsored by the American College of Surgeons and the American Cancer Society. It includes patient data from $>1,500$ accredited facilities and captures $>70 \%$ of newly diagnosed cancer cases in the United States. ${ }^{22}$ The data used in the study are derived from a deidentified NCDB file. The American College of Surgeons and the Commission on Cancer have not verified and are not responsible for the analytic or statistical methodology used, or the conclusions drawn from these data by the investigators.

\section{Patient Cohort Definition}

Using the NCDB, a total of 121,290 patients were identified with gastric cancer diagnosed from 2004 to 2015. Patients were excluded if they had histology other than adenocarcinoma, had metastatic disease or unknown metastatic status at presentation, tu- mors with primary site in the gastroesophageal junction, or underwent any surgery of the primary site (including gastrectomy, local tumor destruction, or local excision). Additional exclusions included patients with stage T0, Tis, or T1a disease and those who did not receive any chemotherapy. These criteria are summarized in Figure 1. The final cohort of 4,795 patients was stratified into those receiving CRT $(n=1,479)$ and those receiving chemotherapy alone $(n=3,316)$. These groups were compared on the primary end point of overall survival (OS).

\section{Variable Definitions}

All variables were selected a priori. Demographic variables including age, year of diagnosis, race, insurance status, facility type, and facility location were defined according to their respective data fields in the NCDB data dictionary. ${ }^{23}$ Race was categorized as non-Hispanic white, black, or other (including Hispanic, Asian, and other). Facility regions were grouped into Northeast, South, Midwest, and West regions. Insurance status was grouped into government (Medicare/Medicaid/other), private, or uninsured. Facility volume was calculated within the

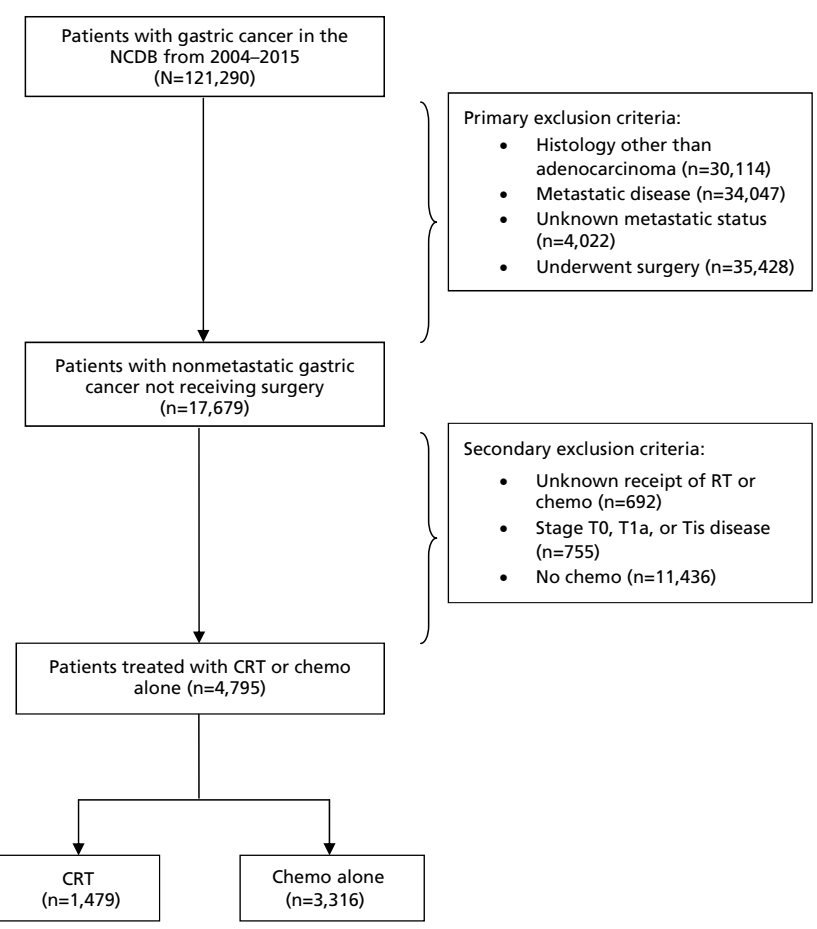

Figure 1. CONSORT diagram illustrating case selection for final patient cohort. Abbreviations: chemo, chemotherapy; CRT, chemoradiation, NCDB, National Cancer Database; RT, radiation therapy. 
Li et al

subset of patients with gastric cancer receiving no surgery, and divided into tertiles by volume (low, medium, high).

For pathologic factors, the $\mathrm{T}$ and $\mathrm{N}$ stages were defined by the clinical $\mathrm{T}$ and $\mathrm{N}$ stage fields, respectively. In cases where a biopsy was performed and a pathologic $\mathrm{T}$ or $\mathrm{N}$ stage was recorded, these were used. AJCC stage group was recorded based on the corresponding field; when missing, the stage group was classified based on the $\mathrm{T}$ and $\mathrm{N}$ staging. Histology of adenocarcinoma was defined using ICD for Oncology, 3rd edition (ICD-O-3) codes, including codes 8140-8145, 8200-8220, 8255-8263, 8320$8384,8400-8490$, and 8550-8574. ${ }^{24}$

For treatment variables, receipt of chemotherapy and RT were defined by their respective fields in the data dictionary. Sequencing of treatment was determined according to the time between diagnosis and initiating that modality of treatment. Concurrent CRT was defined as initiation of chemotherapy and RT no more than 14 days apart; otherwise, CRT was classified as sequential.

\section{Statistical Analysis}

Descriptive statistics for each of the demographic, pathologic, and treatment variables were calculated. OS was plotted using the Kaplan-Meier method with differences across groups assessed using the log-rank statistic. Survival time was calculated from date of diagnosis until date of death or last contact if alive. Patients alive at end of follow-up were censored at last contact date.

Survival analyses were performed using the logrank test for univariate analysis and Cox proportional hazards regression for multivariate analysis to estimate hazard ratios (HRs). The final parsimonious multivariate Cox model was formed by using hierarchical backwards selection of variables significant at $P<.10$. The proportional hazards assumption was assessed for all variables in the final multivariate analysis and was not violated. ${ }^{25}$

A multivariate logistic regression was performed to assess factors predictive of receiving CRT. This was also used to generate propensity scores, with all factors included in propensity score generation regardless of statistical significance-with the exception of AJCC stage grouping, which was omitted due to collinearity with $\mathrm{T}$ and $\mathrm{N}$ staging. We specified a subset analysis a priori to compare HR by AJCC overall stage.

Propensity score-matched (PSM) analysis was performed to compare outcomes for patients receiving CRT to chemotherapy alone. One-to-one nearest neighbor matching without replacement was performed for patients with complete follow-up to form the final propensity-matched cohort, with caliper width of 0.10 . To further support the assumption of balance between groups, the propensity score was stratified into quintiles and a standardized difference between the treatment groups of $<0.10$ was validated. Cox proportional hazards regression was performed for survival analysis in the final matched cohort. Conditional landmark analyses using 3-and 6 -month landmarks were used to mitigate guaranteetime bias.

All statistical analyses were performed using the open-source $\mathrm{R}$ statistical environment (version 3.4.2; R Core Team 2017) and SPSS statistical software (version 23.0; IBM Corporation).

\section{Results}

\section{Patient Cohort Characteristics}

A total of 4,795 patients at a median follow-up of 11.8 months were identified in the NCDB that met the inclusion criteria (Figure 1). Demographic, pathologic, and treatment characteristics of our patient cohort are summarized in Table 1. Most patients were aged $\geq 65$ years $(59.2 \%)$, non-Hispanic white $(55.9 \%)$, and had government insurance (ie, Medicare, Medicaid, other; $60.5 \%$ ).

When stratified by treatment received, 3,316 patients $(69.2 \%)$ received chemotherapy alone and 1,479 patients $(30.8 \%)$ received CRT. Among the 1,479 patients who received CRT, 947 (64.0\%) received concurrent CRT and 524 (35.4\%) received sequential treatment; 8 patients had unknown sequence. No significant difference in survival was seen between those receiving sequential and concurrent treatment. Median time from diagnosis to start of RT was 63 days (interquartile range [IQR], 31-91 days). For those who underwent sequential treatment, median time from start of chemotherapy to start of RT was 64 days (IQR, 22-111 days) and median RT dose among patients receiving CRT was $45 \mathrm{~Gy}$ (IQR, 43.2-50.4 Gy). A total of 536 patients $(36.2 \%)$ received doses $<45 \mathrm{~Gy}$; these patients had a median 
Chemotherapy vs ChemoRT in Unresected Gastric Cancer

\section{Table 1. Baseline Patient Characteristics $(\mathrm{N}=4,795)$}

\begin{tabular}{|c|c|}
\hline Baseline Characteristics & n (\%) \\
\hline \multicolumn{2}{|l|}{ Sociodemographic factors } \\
\hline \multicolumn{2}{|l|}{ Year of diagnosis } \\
\hline 2004-2006 & $921(19.2)$ \\
\hline $2007-2009$ & $1,161(24.2)$ \\
\hline 2010-2012 & $1,229(25.6)$ \\
\hline 2013-2015 & $1,484(30.9)$ \\
\hline \multicolumn{2}{|l|}{ Age, $y$} \\
\hline$<65$ & $1,956(40.8)$ \\
\hline$\geq 65$ & $2,839(59.2)$ \\
\hline \multicolumn{2}{|l|}{ Charlson-Deyo comorbidity score } \\
\hline 0 & $3,465(72.3)$ \\
\hline 1 & $915(19.1)$ \\
\hline$\geq 2$ & $415(8.7)$ \\
\hline \multicolumn{2}{|l|}{ Facility region } \\
\hline Northeast & $1,101(23.0)$ \\
\hline South & $1,804(37.6)$ \\
\hline Midwest & $957(20.0)$ \\
\hline West & $738(15.4)$ \\
\hline Unknown & $195(4.1)$ \\
\hline \multicolumn{2}{|l|}{ Race } \\
\hline Non-Hispanic white & $2,682(55.9)$ \\
\hline Black & $998(20.8)$ \\
\hline Other & $1,082(22.6)$ \\
\hline Unknown & $33(0.7)$ \\
\hline \multicolumn{2}{|l|}{ Insurance status } \\
\hline Government & $2,903(60.5)$ \\
\hline Private & $1,399(29.2)$ \\
\hline Uninsured & $246(5.1)$ \\
\hline Unknown & $247(5.2)$ \\
\hline \multicolumn{2}{|l|}{ Facility volume, tertile } \\
\hline Lowest & $519(10.8)$ \\
\hline Middle & $974(20.3)$ \\
\hline Highest & $3,302(68.9)$ \\
\hline \multicolumn{2}{|l|}{ Facility type } \\
\hline Academic/Research & $2,394(49.9)$ \\
\hline Community/Comprehensive community & $2,206(46.0)$ \\
\hline Unknown & $195(4.1)$ \\
\hline \multicolumn{2}{|l|}{ Pathologic factors } \\
\hline \multicolumn{2}{|l|}{ Anatomic location } \\
\hline NOS & $1,968(41.0)$ \\
\hline Antrum & $1,009(21.0)$ \\
\hline Body & $661(13.8)$ \\
\hline Fundus & $366(7.6)$ \\
\hline Pylorus & $139(2.9)$ \\
\hline Lesser curvature NOS & $450(9.4)$ \\
\hline Greater curvature NOS & $202(4.2)$ \\
\hline \multicolumn{2}{|l|}{ T stage } \\
\hline $\mathrm{T} 1$ & $490(10.2)$ \\
\hline $\mathrm{T} 2$ & $606(12.6)$ \\
\hline $\mathrm{T3}$ & $1,341(28.0)$ \\
\hline $\mathrm{T4}$ & $911(19.0)$ \\
\hline Unknown & $1,447(30.2)$ \\
\hline \multicolumn{2}{|l|}{$\mathrm{N}$ stage } \\
\hline No & $1,857(38.7)$ \\
\hline $\mathrm{N} 1$ & $1,279(26.7)$ \\
\hline $\mathrm{N} 2$ & $398(8.3)$ \\
\hline $\mathrm{N} 3$ & $129(2.7)$ \\
\hline Unknown & $1,132(23.6)$ \\
\hline \multicolumn{2}{|l|}{ AJCC stage group } \\
\hline 1 & $798(16.6)$ \\
\hline II & $1,128(23.5)$ \\
\hline III & $1,389(29.0)$ \\
\hline Unknown & $1,480(30.9)$ \\
\hline Treatment factors & \\
\hline Treatment received & \\
\hline Chemotherapy alone & $3,316(69.2)$ \\
\hline CRT & $1,479(30.8)$ \\
\hline
\end{tabular}

Abbreviations: CRT, chemoradiation; NOS, not otherwise specified. survival of 9 months compared with 14.3 months in those receiving $\geq 45 \mathrm{~Gy}(\log$-rank $P<.001)$.

\section{CRT Use}

Table 2 illustrates the distribution of factors between the CRT group and the chemotherapy-alone group, in addition to odds ratios (ORs) for receipt of CRT. We identified several factors that were predictive of increased CRT use, including age $\geq 65$ years (OR, 1.68; 95\% CI, 1.43-1.99; P<.001), Charlson-Deyo comorbidity score $\geq 2$ (OR, 1.46; 95\% CI, $1.18-1.81 ; P<.001)$, treatment at community facility rather than academic (OR, 1.27; 95\% CI, $1.07-1.51 ; P=.006)$, and T2 disease compared with the reference group of T1 (OR, 1.44; 95\% CI, 1.12$1.85 ; P=.005)$. Factors associated with decreased CRT use were race other than non-Hispanic white or black (OR, 0.76; 95\% CI, 0.64-0.90; $P=.002$ ), year of diagnosis after $2006(P<.001)$, private insurance versus government insurance (OR, 0.85; 95\% CI, 0.73-0.98; P=.024), and treatment at a facility with volume in the highest tertile (OR, 0.81; 95\% CI, 0.69-0.94; $P=.007$ ).

\section{Survival Analysis}

Patients receiving chemotherapy alone had a median survival of 11.3 months and a 2-year OS rate of $21.5 \%$, whereas those receiving CRT had a median survival of 12.3 months and a 2-year OS rate of $28.3 \%$ (log-rank $P<.001)$. Kaplan-Meier curves comparing chemotherapy alone and CRT are depicted in Figure 2A.

The results of multivariate survival analysis are summarized in Table 3. Significant predictors of improved OS included later year of diagnosis, CharlsonDeyo comorbidity score of 0 , nonwhite race, treatment at an academic facility, T stage $<\mathrm{T} 4$, treatment in the Northeast region, and receipt of CRT. After multivariate adjustment, receipt of CRT continued to be significantly associated with improved OS (HR, 0.82; 95\% CI, 0.77-0.89; P<.001). On subset analysis, a survival benefit for CRT was observed in 798 patients with AJCC stage I gastric cancer (HR, $0.72 ; 95 \% \mathrm{CI}, 0.60-0.86 ; \mathrm{P}<.001)$ and 1,128 with AJCC stage II disease (HR, 0.81; 95\% CI, 0.68-0.95; $P=.009$ ). There was a trend toward improvement with CRT but no statistically significant difference in survival between CRT and chemotherapy alone 
Li et al

\begin{tabular}{|c|c|c|c|c|c|}
\hline & $\begin{array}{l}\text { Chemotherapy } \\
(n=3,316)\end{array}$ & $\begin{array}{c}\text { CRT } \\
(n=1,479)\end{array}$ & OR & $95 \% \mathrm{Cl}$ & $P$ Value \\
\hline \multicolumn{6}{|l|}{ Sociodemographic factors } \\
\hline \multicolumn{6}{|l|}{ Year of diagnosis } \\
\hline $2004-2006$ & $614(66.7 \%)$ & $307(33.3 \%)$ & 1 & Ref & \\
\hline $2007-2009$ & $839(72.3 \%)$ & $322(27.7 \%)$ & 0.67 & $0.55-0.82$ & $<.001 *$ \\
\hline $2010-2012$ & $836(68.0 \%)$ & $393(32.0 \%)$ & 0.68 & $0.56-0.82$ & $<.001 *$ \\
\hline $2013-2015$ & $1,027(69.2 \%)$ & $457(30.8 \%)$ & 0.61 & $0.50-0.74$ & $<.001 *$ \\
\hline \multicolumn{6}{|l|}{ Age, y } \\
\hline$<65$ & $1,515(77.5 \%)$ & $441(22.5 \%)$ & 1 & Ref & \\
\hline$\geq 65$ & $1,801(63.4 \%)$ & $1,038(36.6 \%)$ & 1.68 & $1.43-1.99$ & $<.001 *$ \\
\hline \multicolumn{6}{|l|}{ Charlson-Deyo comorbidity score } \\
\hline 0 & $2,443(70.5 \%)$ & $1,022(29.5 \%)$ & 1 & Ref & \\
\hline 1 & $629(68.7 \%)$ & $286(31.3 \%)$ & 1.01 & $0.86-1.19$ & .905 \\
\hline$\geq 2$ & $244(58.8 \%)$ & $171(41.2 \%)$ & 1.46 & $1.18-1.81$ & $.001 *$ \\
\hline \multicolumn{6}{|l|}{ Facility region } \\
\hline Northeast & $788(71.6 \%)$ & $313(28.4 \%)$ & 1 & Ref & \\
\hline South & $1,217(67.5 \%)$ & $587(32.5 \%)$ & 1.22 & $1.03-1.45$ & .021 * \\
\hline Midwest & $624(65.2 \%)$ & $333(34.8 \%)$ & 1.28 & $1.05-1.56$ & $.012^{*}$ \\
\hline West & $521(70.6 \%)$ & $217(29.4 \%)$ & 1.20 & $0.97-1.49$ & .088 \\
\hline Unknown & $166(85.1 \%)$ & $29(14.9 \%)$ & 1.30 & NA & \\
\hline \multicolumn{6}{|l|}{ Race } \\
\hline Non-Hispanic white & $1,793(66.9 \%)$ & $889(33.1 \%)$ & 1 & Ref & \\
\hline Black & $677(67.8 \%)$ & $321(32.2 \%)$ & 1.06 & $0.90-1.25$ & .490 \\
\hline Other & $819(75.7 \%)$ & $263(24.3 \%)$ & 0.76 & $0.64-0.90$ & $.002 *$ \\
\hline Unknown & $27(81.8 \%)$ & $6(18.2 \%)$ & 0.62 & $0.25-1.53$ & .298 \\
\hline \multicolumn{6}{|l|}{ Insurance status } \\
\hline Government & $1,909(65.8 \%)$ & $994(34.2 \%)$ & 1 & Ref & \\
\hline Private & $1,068(76.3 \%)$ & $331(23.7 \%)$ & 0.85 & $0.73-0.98$ & $.024^{*}$ \\
\hline Uninsured & $193(78.5 \%)$ & $53(21.5 \%)$ & 0.94 & NA & \\
\hline Unknown & $146(59.1 \%)$ & $101(40.9 \%)$ & 1.78 & NA & \\
\hline \multicolumn{6}{|l|}{ Facility volume, tertile } \\
\hline Lowest & $328(63.2 \%)$ & $191(36.8 \%)$ & 1 & Ref & \\
\hline Middle & $644(66.1 \%)$ & $330(33.9 \%)$ & 0.90 & $0.76-1.07$ & 241 \\
\hline Highest & $2,344(71.0 \%)$ & $958(29.0 \%)$ & 0.81 & $0.69-0.94$ & $.007 *$ \\
\hline \multicolumn{6}{|l|}{ Facility type } \\
\hline Academic/Research & $1,711(71.5 \%)$ & $683(28.5 \%)$ & 1 & Ref & \\
\hline Community/Comprehensive community & $1,439(65.2 \%)$ & $767(34.8 \%)$ & 1.27 & $1.07-1.51$ & $.006^{*}$ \\
\hline Unknown & $166(85.1 \%)$ & $29(14.9 \%)$ & 0.88 & NA & \\
\hline \multicolumn{6}{|l|}{ Pathologic factors } \\
\hline \multicolumn{6}{|l|}{ T stage } \\
\hline $\mathrm{T} 1$ & $333(68.0 \%)$ & $157(32.0 \%)$ & 1 & Ref & \\
\hline $\mathrm{T} 2$ & $364(60.1 \%)$ & $242(39.9 \%)$ & 1.44 & $1.12-1.85$ & $.005 *$ \\
\hline $\mathrm{T} 3$ & $873(65.1 \%)$ & $468(34.9 \%)$ & 1.19 & $0.95-1.49$ & .139 \\
\hline T4 & $641(70.4 \%)$ & $270(29.6 \%)$ & 1.05 & $0.82-1.33$ & .716 \\
\hline Unknown & $1,105(76.4 \%)$ & $342(23.6 \%)$ & 0.84 & $0.65-1.07$ & 157 \\
\hline \multicolumn{6}{|l|}{$\mathrm{N}$ stage } \\
\hline NO & $1,211(65.2 \%)$ & $646(34.8 \%)$ & 1 & Ref & \\
\hline N1 & $878(68.6 \%)$ & $401(31.4 \%)$ & 0.90 & $0.77-1.06$ & .202 \\
\hline N2 & $251(63.1 \%)$ & $147(36.9 \%)$ & 1.21 & $0.95-1.54$ & .115 \\
\hline N3 & $89(69.0 \%)$ & $40(31.0 \%)$ & 0.98 & $0.66-1.46$ & .928 \\
\hline Unknown & 887 (78.4\%) & $245(21.6 \%)$ & 0.60 & $0.48-0.75$ & $<.001 *$ \\
\hline \multicolumn{6}{|l|}{ AJCC stage group } \\
\hline 1 & $513(64.3 \%)$ & $285(35.7 \%)$ & & & \\
\hline II & $750(66.5 \%)$ & $378(33.5 \%)$ & & & \\
\hline III & 934 (67.2\%) & $455(32.8 \%)$ & & & \\
\hline Unknown & $1,119(75.6 \%)$ & $361(24.4 \%)$ & & & \\
\hline
\end{tabular}

Abbreviations: CRT, chemoradiation; NA, not applicable; OR, odds ratio.

*Statistically significant

in 1,389 patients with stage III cancer (HR, 0.90; 95\% CI, 0.79-1.02; $P=.106)$.

Conditional landmark analyses at time points of 3 and 6 months were performed, excluding patients who were lost to follow-up or who died before the specified landmark. In the 3-month conditional landmark analysis, CRT was associated with improved OS in a sample of 3,885 patients (HR, 0.86; 95\% CI, 0.80-0.93; P<.001). In the 6-month conditional landmark analysis, CRT was associated with 
A

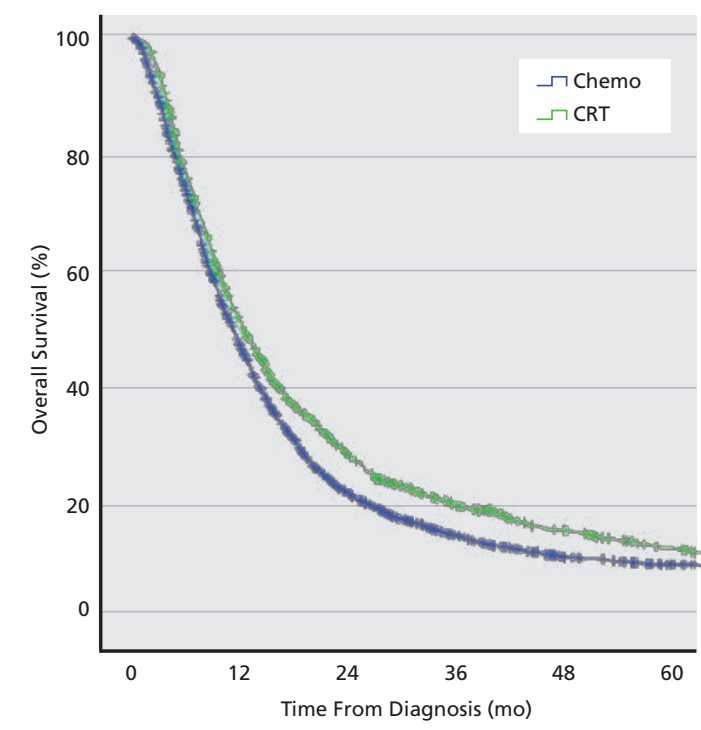

Number at risk

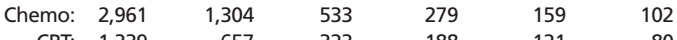

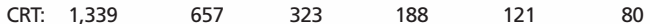

B

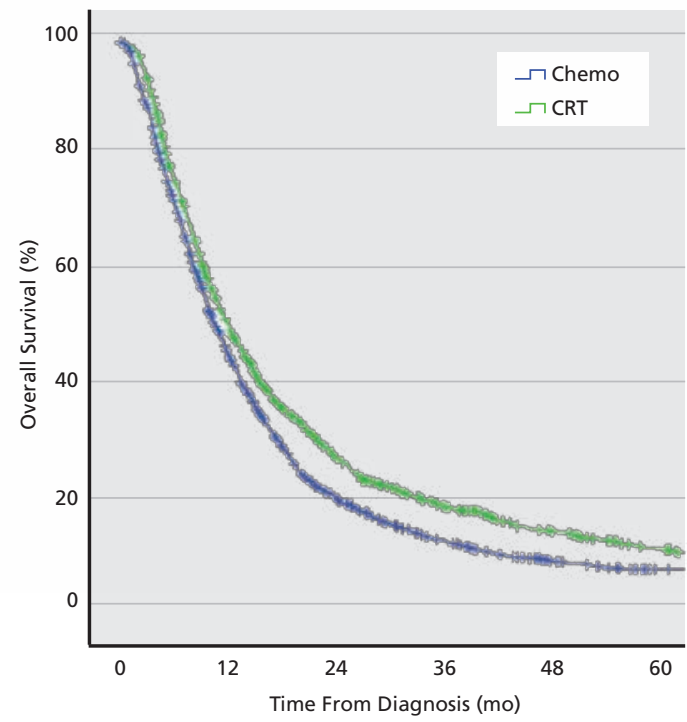

Number at risk

\begin{tabular}{|c|c|c|c|c|c|}
\hline Chemo: & 1,339 & 581 & 237 & 121 & 67 \\
\hline CRT: & 1,339 & 657 & 323 & 188 & 121 \\
\hline
\end{tabular}

Figure 2. Survival analysis of patients treated with chemotherapy (chemo) alone or chemoradiation (CRT). (A) Kaplan-Meier curves of survival without adjustment. (B) Kaplan-Meier curves of survival with adjustment using propensity score matching for CRT use.

improved OS in a sample of 3,140 patients (HR, 0.83; 95\% CI, 0.76-0.91; $P<.001)$.

\section{PSM Analysis}

PSM was performed, adjusting for CRT use. A total of 2,678 patients with complete follow-up data were included in the final matched cohort: 1,339 receiving CRT and 1,339 receiving chemotherapy alone. Fig- ure 2B illustrates Kaplan-Meier survival curves, and Table 4 shows the results of Cox proportional hazards regression in the matched cohort. After adjustment for CRT use with PSM, CRT was persistently associated with improved OS compared with chemotherapy alone (HR, 0.80; 95\% CI, 0.74-0.88; P<.001).

\section{Discussion}

To our knowledge, this is the first published study in the contemporary era comparing CRT with chemotherapy alone for nonmetastatic gastric cancer.

\begin{tabular}{|c|c|c|}
\hline Significant Factors & $\begin{array}{l}\text { Hazard of Death } \\
(95 \% \mathrm{Cl})\end{array}$ & $P$ Value \\
\hline \multicolumn{3}{|l|}{ Year of diagnosis } \\
\hline $2004-2006$ & Ref & \\
\hline 2007-2009 & $0.88(0.80-0.96)$ & $.005^{*}$ \\
\hline 2010-2012 & $0.80(0.73-0.88)$ & $<.001 *$ \\
\hline $2013-2015$ & $0.74(0.67-0.83)$ & $<.001$ * \\
\hline \multicolumn{3}{|l|}{ Age, $y$} \\
\hline$<65$ & Ref & \\
\hline$\geq 65$ & $1.08(1.01-1.17)$ & $.030^{*}$ \\
\hline \multicolumn{3}{|l|}{ Charlson-Deyo comorbidity score } \\
\hline 0 & Ref & \\
\hline 1 & $1.08(0.99-1.18)$ & .074 \\
\hline$\geq 2$ & $1.21(1.07-1.36)$ & $.002 *$ \\
\hline \multicolumn{3}{|l|}{ Facility region } \\
\hline Northeast & Ref & \\
\hline South & $1.13(1.03-1.23)$ & $.009^{*}$ \\
\hline Midwest & $1.28(1.16-1.42)$ & $<.001 *$ \\
\hline West & $1.20(1.07-1.34)$ & $.002 *$ \\
\hline Unknown & NA & \\
\hline \multicolumn{3}{|l|}{ Race } \\
\hline Non-Hispanic white & Ref & \\
\hline Black & $0.84(0.77-0.92)$ & $<.001$ * \\
\hline Other & $0.69(0.63-0.75)$ & $<.001$ * \\
\hline Unknown & $0.82(0.55-1.23)$ & .344 \\
\hline \multicolumn{3}{|l|}{ Facility type } \\
\hline Academic/Research & Ref & \\
\hline $\begin{array}{l}\text { Community/Comprehensive } \\
\text { community }\end{array}$ & $1.11(1.04-1.19)$ & .003 \\
\hline Unknown & NA & \\
\hline \multicolumn{3}{|l|}{ T stage } \\
\hline $\mathrm{T} 1$ & Ref & \\
\hline $\mathrm{T} 2$ & $0.97(0.84-1.12)$ & .658 \\
\hline T3 & $0.99(0.87-1.13)$ & .906 \\
\hline $\mathrm{T} 4$ & $1.29(1.13-1.47)$ & $<.001$ * \\
\hline Unknown & $1.08(0.95-1.24)$ & .246 \\
\hline \multicolumn{3}{|l|}{$\mathrm{N}$ stage } \\
\hline No & Ref & \\
\hline $\mathrm{N} 1$ & $1.02(0.94-1.12)$ & .591 \\
\hline $\mathrm{N} 2$ & $1.14(1.00-1.31)$ & .059 \\
\hline $\mathrm{N} 3$ & $1.12(0.89-1.41)$ & .352 \\
\hline Unknown & $1.25(1.13-1.39)$ & $<.001$ * \\
\hline \multicolumn{3}{|l|}{ Treatment received } \\
\hline Chemotherapy alone & Ref & \\
\hline CRT & $0.82(0.77-0.89)$ & $<.001 *$ \\
\hline
\end{tabular}

Abbreviations: CRT, chemoradiation; NA, not applicable; OS, overall survival. *Statistically significant. 
Li et al

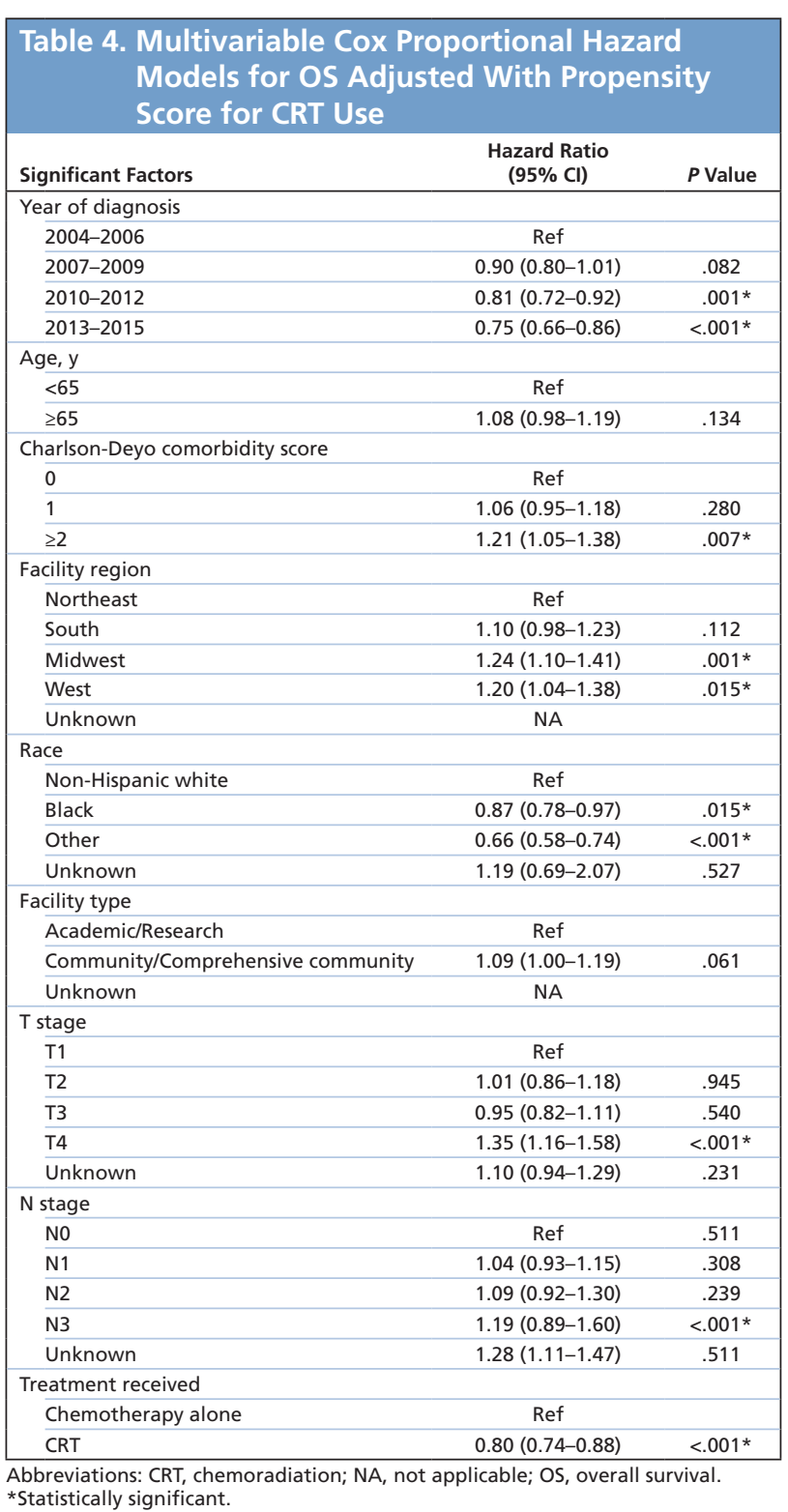

We found that, in the absence of surgical resection, receipt of CRT was associated with significantly improved survival compared with chemotherapy alone. On subset analysis, a survival benefit was seen for patients with overall stage I and II gastric cancer and a trend toward benefit in those with stage III cancer.

Three previous trials have investigated nonsurgical management of locally advanced gastric cancer, although all used outdated chemotherapy and RT techniques. A randomized trial from the Mayo Clinic published in 1969 found a benefit for combined CRT, with a 5 -year OS rate of $12 \%$ versus $0 \%$ in those receiving chemotherapy alone. ${ }^{19}$ A GITSG trial published in 1982 demonstrated improved survival at 4 years when adding RT to 5 -FU and methyl-CCNU ${ }^{18}$; a subsequent GITSG trial that added doxorubicin found no benefit for RT. ${ }^{17}$ In the modern era, no trials have compared chemotherapy and CRT in the definitive setting. In the adjuvant setting, prior studies suggest a benefit for RT in cases of inadequate surgery. The Intergroup 0116 trial found that adjuvant CRT was associated with an improvement in 3-year OS compared with observation. ${ }^{6}$ This survival benefit is frequently attributed to inadequate nodal dissection due to $54 \%$ of patients undergoing DO nodal dissection. Additionally, post hoc analysis of the Dutch Gastric Cancer Group randomized trial of D1 versus D2 nodal dissection found benefit for adjuvant CRT in patients with D1 nodal dissection or positive surgical margins. ${ }^{26}$ Other retrospective analyses have also consistently found OS benefit for CRT in patients with positive surgical margins or inadequate nodal dissection. ${ }^{27-29}$

Our findings are consistent with the current NCCN Guidelines delineating CRT as a treatment option for unresectable stage I-III gastric cancer, with our analysis showing improved survival associated with CRT compared with chemotherapy alone. ${ }^{14}$ Furthermore, these findings suggest that CRT should be incorporated into other guidelines, such as those from ESMO and JGCA, which currently do not mention CRT as a potential treatment regimen. ${ }^{15,16}$ We note that the NCDB captures only US patients. The overall rate of CRT use in our cohort was $30.8 \%$, but other countries may have significantly lower rates due to the omission of this treatment option from their guidelines.

In our study, patients receiving CRT had a 2-year OS rate of $28.3 \%$ and median survival of 12.3 months versus $21.5 \%$ and 11.3 months, respectively, for the chemotherapy-alone group. We speculate that our study may actually underestimate the true survival benefit of CRT. First, we included patients receiving palliative and definitive doses of RT to avoid biasing our comparison. In some patients, RT may have been delivered with the intention of palliating bleeding or obstructive symptoms, rather than for definitive treatment. Additionally, we observed indications of adverse selection bias in the CRT group, as CRT use was associated with several adverse risk factors, including higher comorbidity score and older age. Finally, the HR was more favorable for CRT after propensity score adjustment (0.82 vs 0.80). Indeed, 2 recent phase II 
trials investigating CRT regimens demonstrated considerably superior survival outcomes: Wydmanski et $\mathrm{al}^{20}$ and Liu et $\mathrm{al}^{21}$ reported median survivals of 17.1 and 25.8 months, respectively, and 3-year OS rates of $48 \%$ and $52 \%$, respectively.

These results have additional implications for the design of clinical trials. We conducted a search using the terms "unresectable," "inoperable," and "gastric cancer" on ClinicalTrials.gov and identified at least 10 currently ongoing phase I/II trials investigating chemotherapy-alone regimens as first-line therapy, with eligibility criteria grouping metastatic gastric cancer with locally advanced, unresectable gastric cancer (ClinicalTrials.gov identifiers: NCT00515411, NCT02076594, NCT00183898, NCT03283761, NCT00952003, NCT01913639, NCT03281369, NCT02746796, NCT02504229, NCT01295086). Numerous completed trials on ClinicalTrials.gov and several recently published studies have similar eligibility criteria. ${ }^{30-32}$ We hypothesize that the lower CRT use in academic versus community centers observed in our analysis is partly due to enrollment into such trials. Clinicians should have a comprehensive, individualized discussion of treatment options, including CRT for patients undergoing therapy for nonmetastatic disease.

Our study is subject to the usual biases of retrospective database studies, including limitations in the ability to control for confounding variables and variation in survival data collection methods. ${ }^{33} \mathrm{We}$ also note several limitations of the NCDB that are relevant to the current analysis. First, the NCDB does not contain any information regarding treatment intent. Both chemotherapy and CRT regimens aimed at conversion to resectability have shown promising results. ${ }^{34-38}$ However, patients who convert to resectability and proceed to surgery as a result of initial treatment were excluded from our comparison. Additionally, patients treated with neoadjuvant chemotherapy with initial intent for surgery who did not proceed to resection or those treated with initial intent for sequential CRT who did not receive $\mathrm{RT}$, were included in the chemotherapyalone group. Second, all patients in this sample were clinically staged, and therefore evaluation of $\mathrm{T}$ and $\mathrm{N}$ stage was limited, with many patients marked as unknown. Third, guarantee-time bias could potentially have skewed our results, although we sought to mitigate this effect through a conditional landmark analysis. Despite these limitations, the large sample of patients in this study provides considerable value in the absence of randomized data.

\section{Conclusions}

We found that CRT was associated with improved survival compared with chemotherapy alone in patients with unresected stage I-III gastric cancer. Only $30.8 \%$ of patients in this population received CRT. This survival benefit for CRT is discordant with European and Japanese treatment guidelines, as well as eligibility criteria for numerous ongoing clinical trials. Further prospective studies are needed to evaluate the role of RT for these patients.

\section{References}

1. American Cancer Society. Cancer Facts and Figures 2017. Atlanta, GA: American Cancer Society; 2017.

2. Torre LA, Bray F, Siegel RL, et al. Global cancer statistics, 2012. CA Cancer J Clin 2015;65:87-108.

3. Dikken JL, van de Velde CJ, Coit DG, et al. Treatment of resectable gastric cancer. Therap Adv Gastroenterol 2012;5:49-69.

4. Zhang $Z X$, Gu $X Z$, Yin $W B$, et al. Randomized clinical trial on the combination of preoperative irradiation and surgery in the treatment of adenocarcinoma of gastric cardia (AGC) — report on 370 patients. Int J Radiat Oncol 1998;42:929-934.

5. Bang YJ, Kim YW, Yang HK, et al. Adjuvant capecitabine and oxaliplatin for gastric cancer after D2 gastrectomy (CLASSIC): a phase 3 open-label, randomised controlled trial. Lancet 2012;379:315-321.

6. Macdonald JS, Smalley SR, Benedetti J, et al. Chemoradiotherapy after surgery compared with surgery alone for adenocarcinoma of the stomach or gastroesophageal junction. N Engl J Med 2001;345:725-730.

7. Lee J, Lim DH, Kim S, et al. Phase III trial comparing capecitabine plus cisplatin versus capecitabine plus cisplatin with concurrent capecitabine radiotherapy in completely resected gastric cancer with D2 lymph node dissection: the ARTIST trial. J Clin Oncol 2012;30:268-273.
8. Cunningham D, Allum WH, Stenning SP, et al. Perioperative chemotherapy versus surgery alone for resectable gastroesophageal cancer. N Engl J Med 2006;355:11-20.

9. Sakuramoto S, Sasako M, Yamaguchi T, et al. Adjuvant chemotherapy for gastric cancer with S-1, an oral fluoropyrimidine. N Engl J Med 2007;357:1810-1820.

10. Raigani S, Hardacre JM, Kim J, Ammori JB. Trends in the surgical treatment of gastric adenocarcinoma. Ann Surg Oncol 2014;21:569-574.

11. Frohman HA, Martin JT, Le AT, et al. Failure to operate on resectable gastric cancer: implications for policy changes and regionalization. J Surg Res 2017;214:229-239

12. Park JC, Lee YC, Kim JH, et al. Clinicopathological aspects and prognostic value with respect to age: an analysis of 3,362 consecutive gastric cancer patients. J Surg Oncol 2009;99:395-401.

13. Harrison JD, Fielding JW. Prognostic factors for gastric cancer influencing clinical practice. World J Surg 1995;19:496-500.

14. Ajani JA, D’Amico TA, Baggstrom M, et al. NCCN Clinical Practice Guidelines in Oncology: Gastric Vancer. Version 2.2018. Accessed July 12, 2018. To view the most recent version of these guidelines, visit NCCN.org.

15. Smyth EC, Verheij M, Allum W, et al. Gastric cancer: ESMO Clinical Practice Guidelines for diagnosis, treatment and follow-up. Ann Oncol 2016;27:v38-49. 
Li et al

16. Japanese Gastric Cancer Association. Japanese gastric cancer treatment guidelines 2014 (ver. 4). Gastric Cancer 2017;20:1-19.

17. The concept of locally advanced gastric cancer. Effect of treatment on outcome. The Gastrointestinal Tumor Study Group. Cancer 1990;66:2324-2330

18. A comparison of combination chemotherapy and combined modality therapy for locally advanced gastric carcinoma. Gastrointestinal Tumor Study Group. Cancer 1982;49:1771-1777.

19. Moertel CG, Childs DS, Reitemeier RJ, et al. Combined 5-fluorouracil and supervoltage radiation therapy of locally unresectable gastrointestinal cancer. Lancet 1969;2:865-867.

20. Wydmanski J, Grabinska K, Polanowski P, et al. Radiotherapy and chemoradiotherapy as a novel option for the treatment of locally advanced inoperable gastric adenocarcinoma: a phase II study. Mol Clin Oncol 2014;2:1150-1154

21. Liu Y, Zhao G, Xu Y, et al. Multicenter phase 2 study of peri-irradiation chemotherapy plus intensity modulated radiation therapy with concurrent weekly docetaxel for inoperable or medically unresectable nonmetastatic gastric cancer. Int J Radiat Oncol 2017;98:1096-1105.

22. Bilimoria KY, Stewart AK, Winchester DP, Ko CY. The National Cancer Data Base: a powerful initiative to improve cancer care in the United States. Ann Surg Oncol 2008;15:683-690.

23. National Cancer Data Base: Participant User File Data Dictionary. American College of Surgeons website. Available at: http://ncdbpuf.facs. org. Accessed November 13, 2017.

24. International Classification of Diseases for Oncology. ICD-O-3 Online. Interantional Agency for Research on Cancer website. Available at: http:// codes.iarc.fr/. Accessed November 13, 2017.

25. Bellera CA, MacGrogan G, Debled M, et al. Variables with time-varying effects and the Cox model: some statistical concepts illustrated with a prognostic factor study in breast cancer. BMC Med Res Methodol 2010;10:20.

26. Dikken JL, Jansen EP, Cats A, et al. Impact of the extent of surgery and postoperative chemoradiotherapy on recurrence patterns in gastric cancer. J Clin Oncol 2010;28:2430-2436.

27. Stumpf PK, Amini A, Jones BL, et al. Adjuvant radiotherapy improves overall survival in patients with resected gastric adenocarcinoma: a National Cancer Data Base analysis. Cancer 2017;123:3402-3409.
28. Rhome RM, Moshier E, Sarpel U, et al. Predictors of positive margins afte definitive resection for gastric adenocarcinoma and impact of adjuvant therapies. Int J Radiat Oncol 2017;98:1106-1115.

29. Datta J, McMillan MT, Ecker BL, et al. Implications of lymph node staging on selection of adjuvant therapy for gastric cancer in the United States. Ann Surg 2016;263:298-305.

30. Bang YJ, Cho JY, Kim YH, et al. Efficacy of sequential ipilimumab monotherapy versus best supportive care for unresectable locally advanced/ metastatic gastric or gastroesophageal junction cancer. Clin Cancer Res 2017;23:5671-5678.

31. Blum Murphy MA, Qiao W, Mewada N, et al. A phase I/II study of docetaxel, oxaliplatin, and fluorouracil (D-FOX) chemotherapy in patients with untreated locally unresectable or metastatic adenocarcinoma of the stomach and gastroesophageal junction. Am J Clin Oncol 2018;41:321325 .

32. Chi Y, Yang J, Yang S, et al. Phase I dose-finding study of sorafenib with FOLFOX4 as first-line treatment in patients with unresectable locally advanced or metastatic gastric cancer. Chin J Cancer Res 2015;27:239246.

33. Winchester DP, Stewart AK, Phillips JL, Ward EE. The National Cancer Data Base: past, present, and future. Ann Surg Oncol 2000;17:4-7.

34. Kim JH, Park SR, Ryu MH, et al. Phase II study of induction chemotherapy with docetaxel, capecitabine, and cisplatin plus bevacizumab for initially unresectable gastric cancer with invasion of adjacent organs or paraaortic lymph node metastasis. Cancer Res Treat 2018;50:518-529.

35. Uemura N, Kikuchi S, Sato Y, et al. A phase II study of modified docetaxel, cisplatin, and S-1 (mDCS) chemotherapy for unresectable advanced gastric cancer. Cancer Chemother Pharmacol 2017;80:707-713.

36. Wang Y, Zhuang R, Yu Y, et al. Efficacy of preoperative chemotherapy regimens in patients with initially unresectable locally advanced gastric adenocarcinoma: capecitabine and oxaliplatin (XELOX) or with epirubicin (EOX). Oncotarget 2015;7:76298-76307.

37. Fukuchi $M$, Ishiguro $T$, Ogata $K$, et al. Prognostic role of conversion surgery for unresectable gastric cancer. Ann Surg Oncol 2015;22:3618-3624.

38. Saikawa Y, Kubota T, Kumagai K, et al. Phase II study of chemoradiotherapy with S-1 and low-dose cisplatin for inoperable advanced gastric cancer. Int J Radiat Oncol Biol Phys 2008;71:173-179.

\section{Explore Oncology From Every Angle}

\section{JNCCN 360}

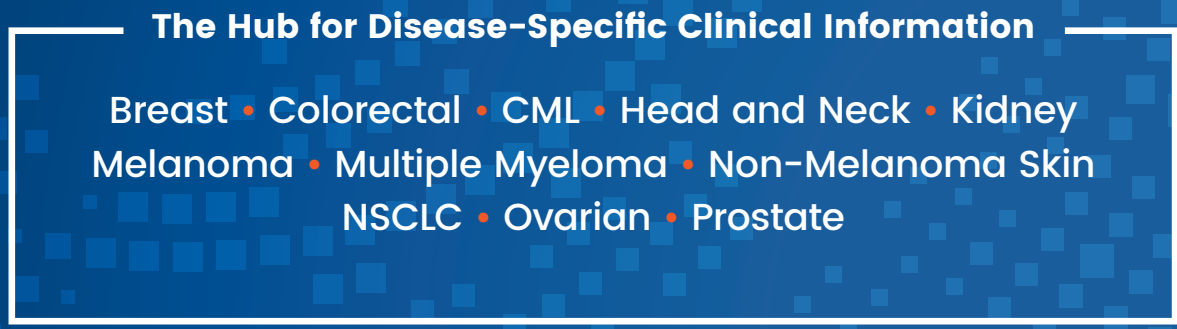

JNCCN360.019

-IARBORSIDE

The nexus of knowledge

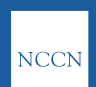

